\title{
Drug cues, conditioned reinforcement and drug seeking: the sequelae of a collaborative venture with Athina Markou
}

\section{Barry J Everitt}

Behavioral and Clinical Neuroscience Institute and Department of Psychology, University of Cambridge

$\begin{array}{ll}\text { Abstract } & 151 \text { words } \\ \text { Text } & 4078 \\ \text { Figures } & 1 \\ \text { Tables } & \text { zero } \\ \text { Supplementary material } & \text { zero }\end{array}$

\section{Correspondence:}

Professor Barry Everitt Department of Psychology University of Cambridge Downing Street Cambridge CB2 3EB UK

e-mail: bje10@cam.ac.uk 


\section{Abstract:}

Athina Markou spent a research period in my laboratory, then in the Department of Anatomy in Cambridge University, in 1991 to help us establish a cocaine-seeking procedure. Thus we embarked on developing a second-order schedule of intravenous cocaine reinforcement in order to investigate the neural basis of the pronounced effects of cocaine-associated conditioned stimuli on cocaine seeking. This brief review summarizes the fundamental aspects of cocaine seeking measured using this approach and the importance of the methodology in enabling us to define the neural mechanisms and circuitry underlying conditioned reinforcement and cocaine, heroin and alcohol seeking. The shift over time and experience of control over drug seeking from a limbic cortical-ventral striatal circuit underlying goal directed drug seeking to a dorsal striatal system mediating habitual drug seeking are also summarised. The theoretical implications of these data are discussed, thereby revealing the ways in which the outcomes of a collaboration can endure. 
Athina Markou was a highly motivated, energetic and inspiring researcher with whom I not only collaborated, but who also became a close friend. I am honored to have this opportunity to summarize what we did together in Cambridge and how this laid the foundations for advances made in the 25 years since she first spent time in Cambridge. It was at the Society for Neuroscience meeting in St Louis that I first met Athina and she discussed with me her emerging interest in the mechanisms by which environmental stimuli become associated with the effects of addictive drugs to influence drug seeking and relapse. Her interest had been sparked by the seminal paper by Gawin and Kleber (1) that established a link to what she had been studying in her outstanding $\mathrm{PhD}$ research with George Koob, namely withdrawal mechanisms and the associated elevated reward thresholds in rats having self-administered cocaine for long periods. This aversive state was argued to model the anhedonia or dysphoria in cocaine-addicted humans in withdrawal that may drive persistent drug taking through negative reinforcement. Gawin and Kleber had described a recognizable withdrawal syndrome in cocaine addiction - something not acknowledged before 1980 - that was not characterized by aversive physical symptoms, but instead by psychological symptoms including depression, anhedonia, anxiety and fatigue (1). However, they also suggested that as these early withdrawal signs begin to dissipate, drug cues become progressively more important in eliciting craving and relapse the longer abstinence is maintained.

Two areas of research that might seem unrelated, but in fact were not, were being undertaken at the time in the Cambridge laboratory. In the first, following Taylor and Robbins' $(2,3)$ demonstration that the potentiative effects of amphetamine on conditioned reinforcement depended on dopamine in the nucleus accumbens, we went on to show that conditioned reinforcement itself depended upon the basolateral amygdala (BLA) (4) and, later, its functional interaction with the nucleus accumbens core (NAcb) (5). In the second, I had been investigating the neural mechanisms of sexual motivation and had developed a second-order schedule of sexual reinforcement in which male rats would seek access to a female rat in heat and once having gained access, would copulate to ejaculation $(6,7)$. This enabled a measure of sexual incentive motivation to be obtained without relying on the measurement of performance, or consummatory, variables such as mounting and intromission. The prolonged period of instrumental responding for a female depended on the presentation of sexassociated conditioned reinforcers (8) and this also depended on the BLA and not the preoptic area, which controls sexual performance in male rats (9).

The plan that Athina Markou and I discussed in St Louis and then corresponded about was to 
establish a second-order schedule of cocaine reinforcement in rats so as to be able to measure (i) the motivation for cocaine without the confound of cocaine's effects on instrumental behavior, and (ii) the impact of drug cues established by Pavlovian association between cocaine's effects and an otherwise neutral stimulus to support seeking behavior by acting as conditioned reinforcers (10). We had no track record in intravenous drug self-administration in Cambridge and so the stage was set for an ideal collaboration and a starting point from which we have never looked back.

Addictive drug-associated conditioned stimuli (CSs) can influence behavior in animals and humans in a number of ways. For example they can elicit automatic approach behavior, thereby bringing the individual into the location of the conditioned stimulus (CS) where drug taking had occurred. This Pavlovian approach behavior - or 'sign-tracking' - elicited by noncontingent presentation of drug cues to rats perhaps resembles the way that drug CSs are presented to addicted individuals in functional imaging experiments, although subjective states (e.g. craving), or sustained attention to, and vigilance for, drug cues, rather than behavioral responses, are more frequently measured in such studies (11-14). While sign tracking of alcohol cues has been demonstrated in rats, especially when the cue is located close to or at the site of alcohol delivery or the response location (15), there are still relatively few demonstrations of sign tracking to cues associated with intravenously self-administered drugs such as cocaine (reviewed in 16).

Conditioned stimuli can also potentiate instrumental seeking responses through a process now referred to as pavlovian-instrumental transfer (PIT), but long known previously as Pavlovian (or conditioned) motivation. The great majority of PIT demonstrations have been in animals responding for ingestive rewards, including alcohol $(17,18)$, but there are only isolated demonstrations of PIT in rats responding for intravenous cocaine, where a modest effect was seen in highly specific circumstances that depended on prior bouts of CS and instrumental extinction (19). PIT has, however, been demonstrated in human subjects in response to a variety of drug and high incentive food CSs with a shift from specific to general PIT in those addicted to drugs (20). In a key demonstration, CS-potentiated smoking in humans was unaffected by satiety and therefore independent of the current incentive value of the drug (cigarette puffs; i.e. no specific PIT), and instead was expressed as a general motivational enhancement (i.e. a general PIT effect), providing evidence therefore of habitual drug use (21, and discussed fully in 22). The neural mechanisms underlying sign-tracking and PIT are dissociable and involve the amygdala, nucleus accumbens core and shell and their 
dopaminergic innervation, as well as related limbic cortical structures. This circuitry has been revealed primarily in studies of rodents responding for ingestive, rather than drug, rewards (and reviewed extensively elsewhere 16, 23, 24, 25).

However, it is the conditioned reinforcing properties of drug-associated CSs that exert the most powerful impact on drug seeking regardless of the procedure used to measure it. The important distinction between conditioned reinforcement and the processes (sign-tracking and PIT) discussed above is that the CS is presented response-contingently; it reinforces the instrumental response, acts as a sub-goal of seeking behavior and thereby enables an animal or human to tolerate and mediate delays to reinforcement (26). A cocaine-associated CS will in fact support the learning of a completely new instrumental seeking response in the absence of any history of primary reinforcement of that response (27) - a canonical test, and measure of the potency, of conditioned reinforcement (28). Once acquired in such an 'acquisition of a new response' procedure, seeking behavior by rats will persist for many weeks being reinforced only by the CS, the animal never having received the primary reinforcer (e.g. cocaine) for making those responses $(27,29)$. In widely used 'extinction-reinstatement' $(30)$, or increasingly used 'incubation of craving' (31) procedures, it is the conditioned reinforcing properties of the CS that underlie 'relapse' - i.e. rats learn instrumentally to respond for the CS, acting as a conditioned reinforcer, in the absence of the self-administered drug after either a period of instrumental (not CS) extinction (i.e. extinction-reinstatement) or a period of abstinence when the behavioral impact of the conditioned reinforcer increases with time in abstinence (i.e. incubation of craving).

In our own studies we have focused on the seeking of drugs under second-order schedules of cocaine (following our earliest experiments with Markou on cocaine 32, 33), heroin, alcohol and high-incentive food reinforcement (see for example 34, 35-38). It should be emphasized that we were far from the first to identify the utility and explore the use of second-order schedules of drug reinforcement in rats. Pioneering studies in the 1970 s by the late Steve Goldberg and colleagues at NIDA (39-41) should be acknowledged for that advance (reviewed in 10). These procedures capture many of the features of foraging for natural or drug rewards in the real world since they incorporate delays to primary drug reinforcement that an animal is able to bridge through the mediating effects of drug conditioned reinforcers. Human subjects seeking cocaine under a second-order schedule of reinforcement in the laboratory also revealed that response-contingent cocaine-associated CSs could maintain behavior even when placebo was ultimately infused rather than the drug (42). 
In the procedure established in our lab by graduate student Mercedes Arroyo and Markou (32), which has changed little ever since, rats are initially trained to make instrumental responses for i.v. infusions of cocaine under a continuous reinforcement schedule (Fixed Ratio (FR) 1). We refer to this as drug taking, to emphasise the low demand simplicity of responding for constantly available drug with no requirement to forage (seek), and that the drug is on-board after the first response and therefore affects all subsequent responses. Each infusion is paired with the presentation of a neutral environmental stimulus (usually a light) such that pavlovian association between drug effect and this increasingly salient stimulus occurs. Subsequently, the now light CS is used to reinforce instrumental responses under high ratio demands and the drug is only actually self-administered after, usually, a fixed interval of 15 minutes. Hence there is a tight relationship between responses and CS presentation, but a weaker relationship between responding and drug infusion. This captures the essence of drug seeking: vigorous responding over delays to reinforcement mediated by the contingent presentation of the CS acting as a conditioned reinforcer (Figure 1A); this is what conditioned reinforcers do in the real world. Each day, rats will work avidly for the CS (usually delivered after every 10 lever presses) and will earn the drug only on completion of the first ratio of 10 responses after the Fixed Interval (usually 15 mins) has elapsed; rats accelerate their responding as the interval progresses and the time of infusion becomes imminent (10) (Figure 1). In the original studies, monkeys were shown to work for 1 hour to receive a single infusion of heroin (43) and in our own studies rats have been shown to work for up to $2 \mathrm{hrs}$ for a single cocaine infusion (while measuring extracellular dopamine in the dorsal and ventral striatum by microdialysis) $(44,45)$. The key here is that behavior in the first interval is a measure of responding for the drug while not under its influence, providing therefore a measure of motivation for the drug and the control over seeking by the drug CS, uncontaminated by the post-administration effects of the drug itself. A particular challenge of the procedure, which may explain why it has not been widely adopted, is that intravenous catheter patency must be maintained for several weeks, up to 3 or 4 months in some of our recent experiments. Markou had faced similar challenges in her thesis work and was key in helping us establish optimal catheterization skills.

Markou and Arroyo made fundamentally important observations in their initial work when considering separately first interval responding, i.e. prior to cocaine infusion, and responding in all subsequent intervals (usually 4 more) in a session. This also marks a distinction between the approach by Goldberg and colleagues who did not treat this first, drugunaffected seeking interval separately from subsequent intervals after the drug had been self- 
administered. Thus, Markou and Arroyo showed the impact of conditioned reinforcement on seeking (Figure 1B) and most importantly that omitting CS presentations resulted in a collapse of seeking responses (Figure 1B,C) - they are still made, but at a very low level thereby providing a direct measure of the impact of drug cues on drug seeking $(32,46)$. They showed a linear relationship between seeking responses and dose of drug in the first interval - the higher the self-administered dose of cocaine, the higher the responding (Figure 1D), but an inverse relationship in later intervals (as in cocaine self-administration under FR:1, as blood drug concentrations are titrated) (32). Further, they showed that self-administered cocaine greatly increased cocaine seeking (Figure 1E,F), reflecting the well-established effects of stimulant drugs to potentiate conditioned reinforcement - an effect mediated by the nucleus accumbens shell (47). Self-administered heroin or alcohol do not have the latter effect and may even depress responding (heroin) (34), providing further support for the desirability of dissociating seeking responses for the drug from instrumental responses under the influence of the drug (10). In a later study it was shown that while self-administered cocaine increased cocaine seeking in second and subsequent intervals, non-contingently administered cocaine had the opposite effect and actually suppressed seeking, perhaps indicating an effect akin to specific satiety, further emphasizing the marked differences in effect of stimulants when self-administered as opposed to when not (33).

At about the time of her visit to Cambridge, Markou had speculated that responding under a second-order schedule might provide a measure of craving induced by drug CSs (48), although she viewed craving as involving not just a subjective state, but also behavioral and physiological responses to drug cues, whereas craving in human studies rarely if ever measures a behavioral variable. It is of course impossible to know whether the drug seeking maintained by conditioned reinforcers presented under a second-order schedule is in any way accompanied by a subjective state of craving or drug 'wanting' (49). It is equally unclear whether the 'incubation craving' measured as increased responding with conditioned reinforcement after abstinence $(31,50,51)$, is in fact accompanied by a subjective craving state that underlies the motivation to seek drugs.

While it may be difficult to appreciate that when a rat presses a lever for a conditioned or primary reinforcer it may not be doing so because it 'wants' or 'craves' it, i.e. it may not be the expression of a goal-directed behavior. Contemporary analysis of instrumental behavior has shown emphatically that this is not the case under circumstances of extended training (52). Conditioned stimuli can elicit and maintain instrumental behavior directly, independent of the 
representation of the value of the goal, through the formation of stimulus-response (S-R) associations that underlie habits. The nature and importance of habits remains a matter of controversy to some authors, who confuse habits (which involve the initiation of a cognitive or behavioral sequence) with skills (which pertain to the performance of a behavioral sequence) (53). However, it has been shown in rats responding for ingestive and drug reinforcers that instrumental seeking responses persist when the reward has been devalued, providing direct evidence that the behavior is at that stage, and prior to the devaluation test, not goal-directed, but habitual (food 52, 54, drug 55, 56). As will be discussed below, a transition from goal-directed to habitual instrumental behavior is accompanied by a shift to control over that behavior by the dorsolateral striatum $(35,57)$. Moreover, using the acquisition of a new response procedure that isolates and measures conditioned reinforcement, it has been shown that responding persists after reinforcer devaluation, i.e. the conditioned reinforcing properties of the CS are resistant to devaluation of the associated primary reinforcer, whereas sign-tracking elicited by the same CS is not (58). Indeed, when rats have been responding for a cocaine-associated CS in the acquisition of new response procedure for 4-8 weeks, responding becomes sensitive to dorsolateral striatal inactivation (59), further evidencing S-R control after initial acquisition. There is considerable evidence that automatic processes underlying seeking habits emerge in humans relapsing to drug use, and that in humans, post-hoc rationalization of such behavior may underlie subjective craving $(60)$.

Having established the methodology when Markou and Arroyo worked together in Cambridge, we have gone on to use it to explore the neural basis of the impact of conditioned reinforcement on drug seeking (Figure 1G) (reviewed in detail in (61-63). We initially showed that the BLA is required for the acquisition of cocaine seeking, as we had predicted from our earlier demonstration of its key role in conditioned reinforcement (4); rats without a BLA acquired cocaine (and heroin) self-administration - hence it had no effect on primary cocaine reinforcement processes - but severely impaired cocaine seeking acquisition (64). Lesions or inactivation of the nucleus accumbens core (NAcbC) also impaired the acquisition of cocaine seeking, whereas lesions of the shell (NAcbS) did not (47), but instead abolished the potentiative effects of cocaine on conditioned reinforcement (shown in Figure 1D). The NAcb was later shown to be a critical site for mediating other amygdala-dependent Pavlovian influences on appetitive behavior $(23,65)$ and also for enabling animals to tolerate delays to reinforcement in an immediate versus delayed reward task; lesions of the NAcbC resulting in impulsive choice and intolerance of delays to reinforcement (66). We then showed that 
dopamine and glutamate-dependent functional interactions between the BLA and NAcbC are required for cocaine seeking using an asymmetric disconnection procedure (67). This has recently been confirmed by showing that the selective DREADD-mediated inhibition of this pathway prevents the seeking response-enhancing effects of contingent presentation of cocaine CSs on introduction of a second-order schedule of reinforcement (Higueras Matas, Puaud, Belin and Everitt, unpublished observations).

An important later realization was that although ventral striatal circuitry is required for the acquisition of cocaine seeking, it actually recruits and then becomes subordinate to dorsal striatal circuitry when the behavior is well established. We had initially hypothesised that while drug seeking is initiated as a goal-directed behavior, after time and multiple daily repetitions of performance of the behavior it eventually becomes controlled by S-R associative processes in the dorsal striatum, and hence our hypothesis of a transition from the ventral to the dorsal striatum of CS-controlled drug seeking over time $(68,69)$. Having initially shown that extracellular dopamine was increased in the NAcbC when cocaine CSs were presented unexpectedly and not response-contingently, but not during well established cocaine seeking under a second-order schedule, we went on to show that it was instead increased in the anterior dorsolateral striatum (aDLS) (45). This increased aDLS dopamine was shown to be causally involved, since dopamine receptor antagonism in the aDLS, but not in the NAcbC, dose-dependently reduced well-established cocaine seeking (70). In retrospect, these data were not as surprising as they seemed at the time, since the aDLS had by then been shown to be essential for S-R habit acquisition and performance of instrumental responding for ingestive rewards $(57,71)$. In addition, we demonstrated that dopamine in the dorsomedial striatum was required for the early acquisition of cocaine seeking (36), consistent with its established role in action-outcome (goal-directed) instrumental behavior (72), but that this dependence becomes subordinate to aDLS control when the behavior is well-established (36).

In investigating the mechanisms by which the transition from ventral to dorsal striatal control over behavior might occur, we tested the hypothesis that it might be mediated by the circuitry that links the nucleus accumbens with the dorsal striatum via recurrent, or spiraling, loops linking progressively more dorsal domains of the striatum through connectivity with midbrain dopamine neurons (Figure 1G) initially revealed in primates (73), but later in the rat brain (74). To demonstrate this, we employed a disconnection procedure in which a unilateral lesion of the NAcbC was combined with contralateral dopamine receptor 
antagonism in the aDLS. This manipulation, which disconnects the circuitry bilaterally, only impaired cocaine seeking when it was well-established; the same manipulation had no effect on instrumental reward seeking soon after acquisition, when goal-directed (35). Subsequently, using in vivo voltammetry CS-elicited cocaine seeking was shown to be associated with dopamine transients in the aDLS, but only after 3 weeks of training, whereas they are present in the NAcb from the outset. Moreover, a unilateral lesion of the NAcbC prevented the late-emerging increase in aDLS dopamine transients only on the side of the brain ipsilateral to the lesion, confirming the dependence of aDLS dopamine release on antecedent ventral striatal processing in animals responding for cocaine (75).

We have explored further the neural circuits that orchestrate these intrastriatal shifts and the associated establishment of cocaine seeking habits by using a combination of asymmetric pharmacological manipulations of the amygdala and aDLS and in vivo extracellular electrophysiological recordings (76). First, it is clear that the CS influence on drug seeking (conditioned reinforcement) initially depends on processing in the amygdala and its interactions with the NAcbC, yet ultimately depends on the aDLS to which the amygdala does not directly project. The functional recruitment of dopamine-dependent aDLS control over cocaine seeking initially depends upon the BLA, but the maintenance of the cocaine seeking habit was shown to depend on the central amygdala (CeN) and its dopamine-dependent interaction with the aDLS (76). Thus, disconnection of the BLA and aDLS impaired cocaine seeking as habitual seeking emerged, but was without effect when well established, while a CeN-aDLS disconnection had no effect early on, but resulted in disruption of cocaine seeking when well established (76). How is the underlying circuitry organized, given the absence of amygdala-aDLS connectivity? The answer is that the NAcbC is the key interface between the BLA and aDLS (Figure 1G). Thus, while stimulation of the BLA did not drive aDLS medium spiny neurons, it both up- and down-regulated the activity of these neurons driven directly by electrical stimulation of the topographically appropriate glutamatergic input from the motor cortex (M1) (76). Coincident glutamate receptor blockade in the NAcbC completely abolished the ability of the BLA to modulate aDLS neuronal activity. The latency of the gating effects of the BLA on aDLS medium spiny neuron firing (76) suggests a polysynaptic pathway involving serial connections between the ventral striatum and midbrain dopamine neurons innervating the dorsal striatum, but this circuit has yet to be mapped using pathway specific manipulations. Similarly the route via which the CeN influences aDLS function has not been demonstrated, but there is a well-established projection from the CeN to the substantia nigra that has previously been shown to have a functional role in conditioned orienting (77), while 
CeN interactions with the aDLS have been shown to play a key role in habitual responding for food (78). Thus, both CeN interactions with the aDLS and BLA interactions with the aDLS (the latter being mediated by the $\mathrm{NAcbC}$ ) likely both depend on engagement of nigral dopaminergic projections to the dorsal striatum, emphasizing again an important role for dopaminergic mechanisms in addictive behavior, but not restricted to mechanisms of reward.

The underlying neural mechanisms and circuitry that have been revealed in the experiments summarized briefly above are consistent with our underlying hypotheses that there is a transition from goal-directed to habitual drug seeking and a shift from ventral to dorsal striatal control over drug seeking during the emergence of drug addiction $(22,61,62,69)$. It has been very interesting and affirming to see the extent to which functional and structural imaging data in human and clinical studies have supported these hypotheses as we have reviewed recently $(22,79)$. In heroin, alcohol and cocaine addiction there is clear evidence of engagement of dorsal striatal mechanisms and functional coupling between ventral and dorsal striatum (80-82), as well as in a behavioral addiction, compulsive gambling (83). These data are further complemented by those demonstrating the dominant engagement of S$\mathrm{R}$ habit processes in addicted individuals (84-86). However, in no sense are rats seeking and self-administering limited numbers of cocaine infusions each day for several weeks considered to be addicted. Rats with this controlled drug intake history have developed strong, dorsal striatum, dopamine-dependent habitual behavior, but they are not compulsive. In a recent study, Leyton and colleagues (87) have explicitly tested this premise by measuring dopamine release in response to cocaine-associated CSs in recreational cocaine users who explicitly did not meet DSM criteria for severe substance use disorder (i.e. addiction). They showed significantly increased extracellular dopamine in the dorsal striatum, whereas in an early study with volunteers who had received just three doses of amphetamine, presentation of the associated CS increased dopamine in the ventral striatum. These data very closely resemble those from our earlier experiments in rats $(44,45)$. In the addicted state, cocaine cues continue to be associated with increased activation of the dorsal striatum (88), further indicating that the shift to dorsal striatal involvement in addictive behavior is associated with the emergence of S-R habits and that this precedes the development of compulsive drug use, as we have hypothesised $(22,69)$, but this has yet to be explicitly been demonstrated.

\section{Concluding remarks}

This brief review I hope reveals how a brief series of visits of Athina Markou to the Cambridge 
laboratory to immerse herself in the way we - Trevor Robbins, Tony Dickinson and I - had begun to study the neural basis of learning and memory mechanisms in addiction, and to share with us her extensive skills in drug self-administration procedures and a different theoretical approach, enabled considerable progress to be made in the more or less 25 years since. Athina was a highly enthusiastic, energetic, intelligent and committed addiction researcher who went on to make very significant contributions to the field, especially in nicotine addiction. She was also a most treasured friend who will always be missed.

\section{Acknowledgements}

This review is dedicated to the memory of Athina Markou. I express my sincere thanks to the many researchers, past and present, who have collected the data summarised briefly here in meticulously conducted experiments. I am grateful to the Medical Research Council have generously supported this research through a continuous series of programme grants. Finally, I thank David Belin for assembling Figure 1, for critical reading of the manuscript and for his major contribution to our understanding of the neural basis of drug seeking.

\section{Financial Disclosure}

I have no financial disclosures. 


\section{References}

1. Gawin FH, Kleber HD (1986): Abstinence symptomatology and psychiatric diagnosis in cocaine abusers. Clinical observations. Arch Gen Psychiatry. 43:107-113.

2. Taylor JR, Robbins T (1984): Enhanced behavioural control by conditioned reinforcers following microinjections of d-amphetamine into the nucleus accumbens. Psychopharmacology (Berl). 84:405-412.

3. Taylor JR, Robbins T (1986): 6-Hydroxydopamine lesions of the nucleus accumbens, but not of the caudate nucleus, attenuate enhanced responding with reward-related stimuli produced by intra-accumbens d-amphetamine. Psychopharmacology (Berl). 90:390-397.

4. Cador M, Robbins TW, Everitt BJ (1989): Involvement of the amygdala in stimulusreward associations: interaction with the ventral striatum. Neuroscience. 30:77-86.

5. Parkinson JA, Olmstead MC, Burns LH, Robbins TW, Everitt BJ (1999): Dissociation in effects of lesions of the nucleus accumbens core and shell on appetitive pavlovian approach behavior and the potentiation of conditioned reinforcement and locomotor activity by Damphetamine. The Journal of Neuroscience. 19:2401-2411.

6. Everitt BJ, Stacey P (1987): Studies of instrumental behavior with sexual reinforcement in male rats (Rattus norvegicus): II. Effects of preoptic area lesions, castration, and testosterone. J Comp Psychol. 101:407-419.

7. Everitt B, Fray P, Kostarczyk E, Taylor S, Stacey P (1987): Studies of instrumental behavior with sexual reinforcement in male rats (Rattus norvegicus): I. Control by brief visual stimuli paired with a receptive female. J Comp Psychol. 101:395-406.

8. Everitt BJ (1990): Sexual motivation: a neural and behavioural analysis of the mechanisms underlying appetitive and copulatory responses of male rats. Neurosci Biobehav Rev. 14:217-232.

9. Everitt BJ, Cador M, Robbins TW (1989): Interactions between the amygdala and ventral striatum in stimulus-reward associations: studies using a second-order schedule of sexual reinforcement. Neuroscience. 30:63-75.

10. Everitt BJ, Robbins TW (2000): Second-order schedules of drug reinforcement in rats and monkeys: measurement of reinforcing efficacy and drug-seeking behaviour. Psychopharmacology. 153:17-30.

11. Hogarth L, Dickinson A, Duka T (2009): Detection versus sustained attention to drug cues have dissociable roles in mediating drug seeking behavior. Exp Clin Psychopharmacol. 17:21-30. 
12. Bradley BP, Mogg K, Wright T, Field M (2003): Attentional bias in drug dependence: vigilance for cigarette-related cues in smokers. Psychol Addict Behav. 17:66-72.

13. Field M, Cox W (2008): Attentional bias in addictive behaviors: a review of its development, causes, and consequences. Drug Alcohol Depend. 97:1-20.

14. Hogarth L, Dickinson A, Janowski M, Nikitina A, Duka T (2008): The role of attentional bias in mediating human drug-seeking behaviour. Psychopharmacology. 201:29-41.

15. Tomie A, di Poce J, Derenzo C, Pohorecky L (2002): Autoshaping of ethanol drinking: an animal model of binge drinking. Alcohol Alcohol. 37:138-146.

16. Saunders B, Robinson T (2013): Individual variation in resisting temptation: implications for addiction. Neurosci Biobehav Rev. 37:1955-1975.

17. Corbit LH, Janak PH (2007): Ethanol-associated cues produce general pavlovianinstrumental transfer. Alcohol Clin Exp Res. 31:766-774.

18. Milton AL, Schramm MJW, Wawrzynski JR, Gore F, Oikonomou-Mpegeti F, Wang NQ, et al. (2012): Antagonism at NMDA receptors, but not beta-adrenergic receptors, disrupts the reconsolidation of pavlovian conditioned approach and instrumental transfer for ethanolassociated conditioned stimuli. Psychopharmacology (Berl). 219:751-761.

19. LeBlanc KH, Ostlund SB, Maidment NT (2012): Pavlovian-to-Instrumental Transfer in Cocaine Seeking Rats. Behavioral neuroscience. 126:681-689.

20. Hogarth L, Balleine B, Corbit L, Killcross S (2013): Associative learning mechanisms underpinning the transition from recreational drug use to addiction. Ann N Y Acad Sci. 1282:12-24.

21. Hogarth L, Dickinson A, Duka T (2010): The associative basis of cue-elicited drug taking in humans. Psychopharmacology (Berl). 208:337-351.

22. Everitt BJ, Robbins TW (2016): Drug Addiction: Updating Actions to Habits to Compulsions Ten Years On. Annu Rev Psychol. 67:23-50.

23. Cardinal R, Parkinson JA, Hall J, Everitt BJ (2002): Emotion and motivation: the role of the amygdala, ventral striatum, and prefrontal cortex. Neuroscience and biobehavioral reviews, 26: $321-352$.

24. Corbit L, Balleine B (2011): The general and outcome-specific forms of Pavlovianinstrumental transfer are differentially mediated by the nucleus accumbens core and shell. $J$ Neurosci. 31:11786-11794.

25. Allman MJ, DeLeon IG, Cataldo MF, Holland PC, Johnson AW (2010): Learning processes affecting human decision making: An assessment of reinforcer-selective Pavlovian- 
to-instrumental transfer following reinforcer devaluation. J Exp Psychol Anim Behav Process. 36:402-408.

26. Cardinal R, Winstanley CA, Robbins TW, Everitt BJ (2004): Limbic Corticostriatal Systems and Delayed Reinforcement. Annals of the New York Academy of Sciences. 1021:33-50. 27. Di Ciano P, Everitt BJ (2004): Conditioned reinforcing properties of stimuli paired with self-administered cocaine, heroin or sucrose: implications for the persistence of addictive behaviour. Neuropharmacology. 47 Suppl 1:202-213.

28. Mackintosh N (1974): The psychology of animal learning. Oxford: Academic Press.

29. Di Ciano P, Benham-Hermetz J, Fogg AP, Osborne GE (2007): Role of the prelimbic cortex in the acquisition, re-acquisition or persistence of responding for a drug-paired conditioned reinforcer. Neuroscience. 150:291-298.

30. Shaham Y, Shalev U, Lu L, De Wit H, Stewart J (2003): The reinstatement model of drug relapse: history, methodology and major findings. Psychopharmacology. 168:3-20.

31. Pickens C, Airavaara M, Theberge F, Fanous S, Hope B, Shaham Y (2011): Neurobiology of the incubation of drug craving. Trends Neurosci. 34:411-420.

32. Arroyo M, Markou A, Robbins TW, Everitt BJ (1998): Acquisition, maintenance and reinstatement of intravenous cocaine self-administration under a second-order schedule of reinforcement in rats: effects of conditioned cues and continuous access to cocaine. Psychopharmacology (Berl). 140:331-344.

33. Markou A, Arroyo M, Everitt B (1999): Effect of contingent and non-contingent cocaine on drug-seeking behavior measured using a second-order schedule of cocaine reinforcement in rats. Neuropsychopharmacology. 20:542-555.

34. Alderson H, Robbins TW, Everitt BJ (2000): Heroin self-administration under a secondorder schedule of reinforcement: acquisition and maintenance of heroin-seeking behaviour in rats. Psychopharmacology. 153:120-133.

35. Belin D, Everitt BJ (2008): Cocaine seeking habits depend upon dopamine-dependent serial connectivity linking the ventral with the dorsal striatum. Neuron. 57:432-441.

36. Murray JE, Belin D, Everitt BJ (2012): Double dissociation of the dorsomedial and dorsolateral striatal control over the acquisition and performance of cocaine seeking. Neuropsychopharmacology. 37:2456-2466.

37. Giuliano C, Robbins TW, Wille DR, Bullmore ET, Everitt BJ (2013): Attenuation of cocaine and heroin seeking by mu-opioid receptor antagonism. Psychopharmacology (Berl). 227:137-147. 
38. Giuliano C, Goodlett CR, Economidou D, Garcia-Pardo MP, Belin D, Robbins TW, et al. (2015): The Novel mu-Opioid Receptor Antagonist GSK1521498 Decreases Both Alcohol Seeking and Drinking: Evidence from a New Preclinical Model of Alcohol Seeking. Neuropsychopharmacology. 40:2981-2992.

39. Goldberg SR, Kelleher RT, Morse WH (1975): Second-order schedules of drug injection. Fed Proc. 34:1771-1776.

40. Goldberg SR (1973): Comparable behavior maintained under fixed-ratio and secondorder schedules of food presentation, cocaine injection or d-amphetamine injection in the squirrel monkey.J Pharmacol Exp Ther. 186:18-30.

41. Goldberg SR, Spealman RD, Kelleher RT (1979): Enhancement of drug-seeking behavior by environmental stimuli associated with cocaine or morphine injections. Neuropharmacology. 18:1015-1017.

42. Panlilio L, Yasar S, Nemeth-Coslett R, Katz J, Henningfield J, Solinas M, et al. (2005): Human cocaine-seeking behavior and its control by drug-associated stimuli in the laboratory. Neuropsychopharmacology. 30:433-443.

43. Goldberg SR, Morse WH, Goldberg DM (1976): Behavior maintained under a secondorder schedule by intramuscular injection of morphine or cocaine in rhesus monkeys. $J$ Pharmacol Exp Ther. 199:278-286.

44. Ito R, Dalley J, Howes SR, Robbins TW, Everitt BJ (2000): Dissociation in Conditioned Dopamine Release in the Nucleus Accumbens Core and Shell in Response to Cocaine cues and during Cocaine-Seeking Behavior in rats. Journal of Neuroscience. 19:7489-7495.

45. Ito R, Dalley J, Robbins T, Everitt B (2002): Dopamine release in the dorsal striatum during cocaine-seeking behavior under the control of a drug-associated cue. J Neurosci. 22:6247-6253.

46. Di Ciano P, Everitt B (2002): Reinstatement and spontaneous recovery of cocaineseeking following extinction and different durations of withdrawal. Behavioural Pharmacology. 13:397-405.

47. Ito R, Robbins T, Everitt B (2004): Differential control over cocaine-seeking behavior by nucleus accumbens core and shell. Nat Neurosci. 7:389-397.

48. Markou A, Weiss F, Gold LH, Caine SB, Schulteis G, Koob G (1993): Animal models of drug craving. Psychopharmacology (Berl). 112:163-182.

49. Robinson TE, Berridge KC (1993): The neural basis of drug craving: an incentivesensitization theory of addiction. Brain Res Brain Res Rev. 18:247-291. 
50. Grimm JW, Hope BT, Wise RA, Shaham Y (2001): Incubation of cocaine craving after withdrawal. Nature. 412:141-142.

51. Wolf ME (2016): Synaptic mechanisms underlying persistent cocaine craving. Nat Rev Neurosci. 17:351-365.

52. Adams C, Dickinson A (1981): Instrumental responding following reinforcer devaluation. Q J Exp Psychol Comp Physiol Psychol. 33:109-121.

53. Piazza P, Deroche-Gamonet V (2013): A multistep general theory of transition to addiction. Psychopharmacology (Berl). 229:387-413.

54. Balleine B, Paredes-Olay C, Dickinson A (2005): Effects of outcome devaluation on the performance of a heterogeneous instrumental chain. International journal of comparative psychology. 18:257-272.

55. Zapata A, Minney V, Shippenberg T (2010): Shift from goal-directed to habitual cocaine seeking after prolonged experience in rats. J Neurosci. 30:15457-15463.

56. Corbit LH, Chieng BC, Balleine BW (2014): Effects of repeated cocaine exposure on habit learning and reversal by N-acetylcysteine. Neuropsychopharmacology. 39:1893-1901.

57. Yin HH, Knowlton BJ, Balleine BW (2004): Lesions of dorsolateral striatum preserve outcome expectancy but disrupt habit formation in instrumental learning. European Journal of Neuroscience. 19:181-189.

58. Parkinson JA, Roberts AC, Everitt B, Di Ciano P (2005): Acquisition of instrumental conditioned reinforcement is resistant to the devaluation of the unconditioned stimulus. QJExpPsycholB. 58:19-30.

59. Di Ciano P, Robbins TW, Everitt BJ (2008): Differential Effects of Nucleus Accumbens Core, Shell, or Dorsal Striatal Inactivations on the Persistence, Reacquisition, or Reinstatement of Responding for a Drug-Paired Conditioned Reinforcer. Neuropsychopharmacology. 33:1413-1425.

60. Tiffany ST (1990): A cognitive model of drug urges and drug-use behavior: role of automatic and nonautomatic processes. Psychol Rev. 97:147-168.

61. Belin D, Jonkman S, Dickinson A, Robbins TW, Everitt BJ (2009): Parallel and interactive learning processes within the basal ganglia: relevance for the understanding of addiction. Behav Brain Res. 199:89-102.

62. Everitt BJ, Robbins TW (2013): From the ventral to the dorsal striatum: devolving views of their roles in drug addiction. Neurosci Biobehav Rev. 37: 1946-1954 
63. Everitt BJ (2014): Neural and psychological mechanisms underlying compulsive drug seeking habits and drug memories--indications for novel treatments of addiction. Eur $J$ Neurosci. 40:2163-2182.

64. Whitelaw RB, Markou A, Robbins TW, Everitt BJ (1996): Excitotoxic lesions of the basolateral amygdala impair the acquisition of cocaine-seeking behaviour under a secondorder schedule of reinforcement. Psychopharmacology (Berl). 127:213-224.

65. Everitt BJ, Cardinal RN, Parkinson JA, Robbins TW (2003): Appetitive Behavior Impact of Amygdala-Dependent Mechanisms of Emotional Learning. Annals of the New York Academy of Sciences. 985:233-250.

66. Cardinal RN, Pennicott DR, Sugathapala CL, Robbins TW, Everitt BJ (2001): Impulsive choice induced in rats by lesions of the nucleus accumbens core. Science. 292:2499-2501.

67. Di Ciano P, Everitt BJ (2004): Direct Interactions between the Basolateral Amygdala and Nucleus Accumbens Core Underlie Cocaine-Seeking Behavior by Rats. Journal of Neuroscience. 24:7167-7173.

68. Robbins TW, Everitt BJ (1999): Drug addiction: bad habits add up. Nature. 398:567570.

69. Everitt BJ, Robbins TW (2005): Neural systems of reinforcement for drug addiction: from actions to habits to compulsion. Nat Neurosci. 8:1481-1489.

70. Vanderschuren L, Di Ciano P, Everitt B (2005): Involvement of the dorsal striatum in cue-controlled cocaine seeking. J Neurosci. 25:8665-8670.

71. Yin H, Knowlton B, Balleine B (2006): Inactivation of dorsolateral striatum enhances sensitivity to changes in the action-outcome contingency in instrumental conditioning. Behavioural Brain Research. 166:189-196.

72. Yin HH, Ostlund SB, Knowlton BJ, Balleine BW (2005): The role of the dorsomedial striatum in instrumental conditioning. Eur J Neurosci. 22:513-523.

73. Haber S, Fudge J, McFarland N (2000): Striatonigrostriatal pathways in primates form an ascending spiral from the shell to the dorsolateral striatum. J Neurosci. 20:2369-2382.

74. Ikemoto S (2007): Dopamine reward circuitry: Two projection systems from the ventral midbrain to the nucleus accumbens-olfactory tubercle complex. Brain Research Reviews. 56:27-78.

75. Willuhn I, Burgeno LM, Everitt BJ, Phillips PE (2012): Hierarchical recruitment of phasic dopamine signaling in the striatum during the progression of cocaine use. Proc Natl Acad Sci U S A. 109:20703-20708. 
76. Murray JE, Belin-Rauscent A, Simon M, Giuliano C, Benoit-Marand M, Everitt BJ, et al. (2015): Basolateral and central amygdala differentially recruit and maintain dorsolateral striatum-dependent cocaine-seeking habits. Nat Commun. 6:10088.

77. El-Amamy H, Holland P (2007): Dissociable effects of disconnecting amygdala central nucleus from the ventral tegmental area or substantia nigra on learned orienting and incentive motivation. Eur J Neurosci. 25:1557-1567.

78. Lingawi NW, Balleine BW (2012): Amygdala central nucleus interacts with dorsolateral striatum to regulate the acquisition of habits. J Neurosci. 32:1073-1081.

79. Everitt BJ, Giuliano C, Belin D (2017): Addictive behaviour in experimental animals: prospects for translation. Philisophical Transactions of the Royal Society, B. DOI: 10.1098/rstb. 2017.0027

80. Xie C, Shao Y, Ma L, Zhai T, Ye E, Fu L, et al. (2014): Imbalanced functional link between valuation networks in abstinent heroin-dependent subjects. Mol Psychiatry. 19:10-12.

81. Vollstadt-Klein S, Wichert S, Rabinstein J, Buhler M, Klein O, Ende G, et al. (2010): Initial, habitual and compulsive alcohol use is characterized by a shift of cue processing from ventral to dorsal striatum. Addiction. 105:1741-1749.

82. Sjoerds Z, de Wit S, van den Brink W, Robbins TW, Beekman ATF, Penninx BWJH, et al. (2013): Behavioral and neuroimaging evidence for overreliance on habit learning in alcoholdependent patients. Translational Psychiatry. DOI: 10.1038/tp.2013.107

83. Liu L, Yip SW, Zhang JT, Wang LJ, Shen ZJ, Liu B, et al. (2017): Activation of the ventral and dorsal striatum during cue reactivity in Internet gaming disorder. Addict Biol. 22:791-801. 84. Bohbot V, Del Balso D, Conrad K, Konishi K, Leyton M (2013): Caudate nucleusdependent navigational strategies are associated with increased use of addictive drugs. Hippocampus. 23:973-984.

85. Ersche KD, Gillan CM, Jones PS, Williams GB, Ward LH, Luijten M, et al. (2016): Carrots and sticks fail to change behavior in cocaine addiction. Science. 352:1468-1471.

86. Donamayor N, Strelchuk D, Baek K, Banca P, Voon V (2017): The involuntary nature of binge drinking: goal directedness and awareness of intention. Addict Biol.

87. Cox SML, Yau Y, Larcher K, Durand F, Kolivakis T, Delaney JS, et al. (2017): Cocaine Cue-Induced Dopamine Release in Recreational Cocaine Users. Sci Rep. 7:46665.

88. Volkow N, Wang GJ, Telang F, Fowler JS, Logan J, Childress AR, et al. (2006): Cocaine Cues and Dopamine in Dorsal Striatum: Mechanism of Craving in Cocaine Addiction. Journal of Neuroscience. 26:6583-6588. 
BJ Everitt. Biological Psychiatry special issue to commemorate Athina Markou, 2017 
Figure 1. Behavioral characteristics of cocaine seeking under a second-order schedule of reinforcement and the underlying limbic corticostriatal circuitry

1A. Schematic illustration of rats responding for a cocaine-associated light conditioned reinforcer (under a FR10 schedule; i.e.10 active lever presses, ALP) prior to receiving an i.v. infusion of cocaine after a 15 minute fixed interval. 1B The effects of introducing a cocaine CS contingent on every 10 lever presses. In the initial 3 sessions, rats are responding under a Fixed Interval 15 minutes schedule (FI15). On introduction of the CS (sessions 5-10) under FR 10 there is a near quadrupling of seeking responses per 15 minutes (FI15:FR10S secondorder schedule). Omitting the CS (CSO) results in a marked decrease in seeking responses (session 11). 1C. The decrease in seeking responses over 3 days of CS omission from a Pre-CS omission baseline. Seeking responses increase promptly on reintroduction of the cocaine CS. 1D In the first (pre-cocaine infusion) interval of a FI15:FR10S second order schedule is linearly related to drug dose. $1 \mathrm{E} \& \mathrm{~F}$. An individual cumulative response record in a rat responding under FI15:FR10S. Each Fixed Ratio 10 responses results in illumination of the light CS, which early in the 15 minute interval is followed by a post-stimulus pause in responding (i.e. a post conditioned reinforcement pause). As the interval progresses, responding becomes more or less continuous until cocaine is infused on completion of a FR10 of responses after the Fixed Interval has timed out. After the cocaine infusion, in the $2^{\text {nd }} 15$ minute interval, seeking responses are greatly increased, reflecting the effect of cocaine to enhance conditioned reinforcement, an effect that depends on the integrity of the nucleus accumbens shell. 1G. Summary of the circuitry underlying cocaine seeking. Illustrated are basolateral amygdala (BLA) projections to the nucleus accumbens core (AcbC), required for acquisition of cocaine seeking through the mediation of conditioned reinforcement and tolerance of delays to reinforcement. The spiraling circuitry linking nucleus accumbens with more dorsal striatal zones - dorsomedial striatum (DMS) with its afferents from the orbitofrontal cortex (OFc) and the dorsolateral striatum (DLS) is shown as alternating arrows. The DMS is required for the early acquisition of cocaine seeking when goal-directed; the DLS is required for well-established cocaine seeking when under stimulus-response (habitual) control. 


\section{Drug cues, conditioned reinforcement and drug seeking: the sequelae of a collaborative venture with Athina Markou}

\section{Barry J Everitt}

Behavioral and Clinical Neuroscience Institute and Department of Psychology, University of Cambridge

$\begin{array}{ll}\text { Abstract } & 151 \text { words } \\ \text { Text } & 4078 \\ \text { Figures } & 1 \\ \text { Tables } & \text { zero } \\ \text { Supplementary material } & \text { zero }\end{array}$

\section{Correspondence:}

Professor Barry Everitt Department of Psychology University of Cambridge Downing Street Cambridge CB2 3EB UK

e-mail: bje10@cam.ac.uk 


\section{Abstract:}

Athina Markou spent a research period in my laboratory, then in the Department of Anatomy in Cambridge University, in 1991 to help us establish a cocaine-seeking procedure. Thus we embarked on developing a second-order schedule of intravenous cocaine reinforcement in order to investigate the neural basis of the pronounced effects of cocaine-associated conditioned stimuli on cocaine seeking. This brief review summarizes the fundamental aspects of cocaine seeking measured using this approach and the importance of the methodology in enabling us to define the neural mechanisms and circuitry underlying conditioned reinforcement and cocaine, heroin and alcohol seeking. The shift over time and experience of control over drug seeking from a limbic cortical-ventral striatal circuit underlying goal directed drug seeking to a dorsal striatal system mediating habitual drug seeking are also summarised. The theoretical implications of these data are discussed, thereby revealing the ways in which the outcomes of a collaboration can endure. 
Athina Markou was a highly motivated, energetic and inspiring researcher with whom I not only collaborated, but who also became a close friend. I am honored to have this opportunity to summarize what we did together in Cambridge and how this laid the foundations for advances made in the 25 years since she first spent time in Cambridge. It was at the Society for Neuroscience meeting in St Louis that I first met Athina and she discussed with me her emerging interest in the mechanisms by which environmental stimuli become associated with the effects of addictive drugs to influence drug seeking and relapse. Her interest had been sparked by the seminal paper by Gawin and Kleber (1) that established a link to what she had been studying in her outstanding $\mathrm{PhD}$ research with George Koob, namely withdrawal mechanisms and the associated elevated reward thresholds in rats having self-administered cocaine for long periods. This aversive state was argued to model the anhedonia or dysphoria in cocaine-addicted humans in withdrawal that may drive persistent drug taking through negative reinforcement. Gawin and Kleber had described a recognizable withdrawal syndrome in cocaine addiction - something not acknowledged before 1980 - that was not characterized by aversive physical symptoms, but instead by psychological symptoms including depression, anhedonia, anxiety and fatigue (1). However, they also suggested that as these early withdrawal signs begin to dissipate, drug cues become progressively more important in eliciting craving and relapse the longer abstinence is maintained.

Two areas of research that might seem unrelated, but in fact were not, were being undertaken at the time in the Cambridge laboratory. In the first, following Taylor and Robbins' $(2,3)$ demonstration that the potentiative effects of amphetamine on conditioned reinforcement depended on dopamine in the nucleus accumbens, we went on to show that conditioned reinforcement itself depended upon the basolateral amygdala (BLA) (4) and, later, its functional interaction with the nucleus accumbens core (NAcb) (5). In the second, I had been investigating the neural mechanisms of sexual motivation and had developed a second-order schedule of sexual reinforcement in which male rats would seek access to a female rat in heat and once having gained access, would copulate to ejaculation $(6,7)$. This enabled a measure of sexual incentive motivation to be obtained without relying on the measurement of performance, or consummatory, variables such as mounting and intromission. The prolonged period of instrumental responding for a female depended on the presentation of sexassociated conditioned reinforcers (8) and this also depended on the BLA and not the preoptic area, which controls sexual performance in male rats (9).

The plan that Athina Markou and I discussed in St Louis and then corresponded about was to 
establish a second-order schedule of cocaine reinforcement in rats so as to be able to measure (i) the motivation for cocaine without the confound of cocaine's effects on instrumental behavior, and (ii) the impact of drug cues established by Pavlovian association between cocaine's effects and an otherwise neutral stimulus to support seeking behavior by acting as conditioned reinforcers (10). We had no track record in intravenous drug self-administration in Cambridge and so the stage was set for an ideal collaboration and a starting point from which we have never looked back.

Addictive drug-associated conditioned stimuli (CSs) can influence behavior in animals and humans in a number of ways. For example they can elicit automatic approach behavior, thereby bringing the individual into the location of the conditioned stimulus (CS) where drug taking had occurred. This Pavlovian approach behavior - or 'sign-tracking' - elicited by noncontingent presentation of drug cues to rats perhaps resembles the way that drug CSs are presented to addicted individuals in functional imaging experiments, although subjective states (e.g. craving), or sustained attention to, and vigilance for, drug cues, rather than behavioral responses, are more frequently measured in such studies (11-14). While sign tracking of alcohol cues has been demonstrated in rats, especially when the cue is located close to or at the site of alcohol delivery or the response location (15), there are still relatively few demonstrations of sign tracking to cues associated with intravenously self-administered drugs such as cocaine (reviewed in 16).

Conditioned stimuli can also potentiate instrumental seeking responses through a process now referred to as pavlovian-instrumental transfer (PIT), but long known previously as Pavlovian (or conditioned) motivation. The great majority of PIT demonstrations have been in animals responding for ingestive rewards, including alcohol $(17,18)$, but there are only isolated demonstrations of PIT in rats responding for intravenous cocaine, where a modest effect was seen in highly specific circumstances that depended on prior bouts of CS and instrumental extinction (19). PIT has, however, been demonstrated in human subjects in response to a variety of drug and high incentive food CSs with a shift from specific to general PIT in those addicted to drugs (20). In a key demonstration, CS-potentiated smoking in humans was unaffected by satiety and therefore independent of the current incentive value of the drug (cigarette puffs; i.e. no specific PIT), and instead was expressed as a general motivational enhancement (i.e. a general PIT effect), providing evidence therefore of habitual drug use (21, and discussed fully in 22). The neural mechanisms underlying sign-tracking and PIT are dissociable and involve the amygdala, nucleus accumbens core and shell and their 
dopaminergic innervation, as well as related limbic cortical structures. This circuitry has been revealed primarily in studies of rodents responding for ingestive, rather than drug, rewards (and reviewed extensively elsewhere 16, 23, 24, 25).

However, it is the conditioned reinforcing properties of drug-associated CSs that exert the most powerful impact on drug seeking regardless of the procedure used to measure it. The important distinction between conditioned reinforcement and the processes (sign-tracking and PIT) discussed above is that the CS is presented response-contingently; it reinforces the instrumental response, acts as a sub-goal of seeking behavior and thereby enables an animal or human to tolerate and mediate delays to reinforcement (26). A cocaine-associated CS will in fact support the learning of a completely new instrumental seeking response in the absence of any history of primary reinforcement of that response (27) - a canonical test, and measure of the potency, of conditioned reinforcement (28). Once acquired in such an 'acquisition of a new response' procedure, seeking behavior by rats will persist for many weeks being reinforced only by the $\mathrm{CS}$, the animal never having received the primary reinforcer (e.g. cocaine) for making those responses $(27,29)$. In widely used 'extinction-reinstatement' $(30)$, or increasingly used 'incubation of craving' (31) procedures, it is the conditioned reinforcing properties of the CS that underlie 'relapse' - i.e. rats learn instrumentally to respond for the CS, acting as a conditioned reinforcer, in the absence of the self-administered drug after either a period of instrumental (not CS) extinction (i.e. extinction-reinstatement) or a period of abstinence when the behavioral impact of the conditioned reinforcer increases with time in abstinence (i.e. incubation of craving).

In our own studies we have focused on the seeking of drugs under second-order schedules of cocaine (following our earliest experiments with Markou on cocaine 32, 33), heroin, alcohol and high-incentive food reinforcement (see for example 34, 35-38). It should be emphasized that we were far from the first to identify the utility and explore the use of second-order schedules of drug reinforcement in rats. Pioneering studies in the 1970 s by the late Steve Goldberg and colleagues at NIDA (39-41) should be acknowledged for that advance (reviewed in 10). These procedures capture many of the features of foraging for natural or drug rewards in the real world since they incorporate delays to primary drug reinforcement that an animal is able to bridge through the mediating effects of drug conditioned reinforcers. Human subjects seeking cocaine under a second-order schedule of reinforcement in the laboratory also revealed that response-contingent cocaine-associated CSs could maintain behavior even when placebo was ultimately infused rather than the drug (42). 
In the procedure established in our lab by graduate student Mercedes Arroyo and Markou (32), which has changed little ever since, rats are initially trained to make instrumental responses for i.v. infusions of cocaine under a continuous reinforcement schedule (Fixed Ratio (FR) 1). We refer to this as drug taking, to emphasise the low demand simplicity of responding for constantly available drug with no requirement to forage (seek), and that the drug is on-board after the first response and therefore affects all subsequent responses. Each infusion is paired with the presentation of a neutral environmental stimulus (usually a light) such that pavlovian association between drug effect and this increasingly salient stimulus occurs. Subsequently, the now light CS is used to reinforce instrumental responses under high ratio demands and the drug is only actually self-administered after, usually, a fixed interval of 15 minutes. Hence there is a tight relationship between responses and CS presentation, but a weaker relationship between responding and drug infusion. This captures the essence of drug seeking: vigorous responding over delays to reinforcement mediated by the contingent presentation of the CS acting as a conditioned reinforcer (Figure 1A); this is what conditioned reinforcers do in the real world. Each day, rats will work avidly for the CS (usually delivered after every 10 lever presses) and will earn the drug only on completion of the first ratio of 10 responses after the Fixed Interval (usually 15 mins) has elapsed; rats accelerate their responding as the interval progresses and the time of infusion becomes imminent (10) (Figure 1). In the original studies, monkeys were shown to work for 1 hour to receive a single infusion of heroin (43) and in our own studies rats have been shown to work for up to $2 \mathrm{hrs}$ for a single cocaine infusion (while measuring extracellular dopamine in the dorsal and ventral striatum by microdialysis) $(44,45)$. The key here is that behavior in the first interval is a measure of responding for the drug while not under its influence, providing therefore a measure of motivation for the drug and the control over seeking by the drug CS, uncontaminated by the post-administration effects of the drug itself. A particular challenge of the procedure, which may explain why it has not been widely adopted, is that intravenous catheter patency must be maintained for several weeks, up to 3 or 4 months in some of our recent experiments. Markou had faced similar challenges in her thesis work and was key in helping us establish optimal catheterization skills.

Markou and Arroyo made fundamentally important observations in their initial work when considering separately first interval responding, i.e. prior to cocaine infusion, and responding in all subsequent intervals (usually 4 more) in a session. This also marks a distinction between the approach by Goldberg and colleagues who did not treat this first, drugunaffected seeking interval separately from subsequent intervals after the drug had been self- 
administered. Thus, Markou and Arroyo showed the impact of conditioned reinforcement on seeking (Figure 1B) and most importantly that omitting CS presentations resulted in a collapse of seeking responses (Figure 1B,C) - they are still made, but at a very low level thereby providing a direct measure of the impact of drug cues on drug seeking $(32,46)$. They showed a linear relationship between seeking responses and dose of drug in the first interval - the higher the self-administered dose of cocaine, the higher the responding (Figure 1D), but an inverse relationship in later intervals (as in cocaine self-administration under FR:1, as blood drug concentrations are titrated) (32). Further, they showed that self-administered cocaine greatly increased cocaine seeking (Figure 1E,F), reflecting the well-established effects of stimulant drugs to potentiate conditioned reinforcement - an effect mediated by the nucleus accumbens shell (47). Self-administered heroin or alcohol do not have the latter effect and may even depress responding (heroin) (34), providing further support for the desirability of dissociating seeking responses for the drug from instrumental responses under the influence of the drug (10). In a later study it was shown that while self-administered cocaine increased cocaine seeking in second and subsequent intervals, non-contingently administered cocaine had the opposite effect and actually suppressed seeking, perhaps indicating an effect akin to specific satiety, further emphasizing the marked differences in effect of stimulants when self-administered as opposed to when not (33).

At about the time of her visit to Cambridge, Markou had speculated that responding under a second-order schedule might provide a measure of craving induced by drug CSs (48), although she viewed craving as involving not just a subjective state, but also behavioral and physiological responses to drug cues, whereas craving in human studies rarely if ever measures a behavioral variable. It is of course impossible to know whether the drug seeking maintained by conditioned reinforcers presented under a second-order schedule is in any way accompanied by a subjective state of craving or drug 'wanting' (49). It is equally unclear whether the 'incubation craving' measured as increased responding with conditioned reinforcement after abstinence $(31,50,51)$, is in fact accompanied by a subjective craving state that underlies the motivation to seek drugs.

While it may be difficult to appreciate that when a rat presses a lever for a conditioned or primary reinforcer it may not be doing so because it 'wants' or 'craves' it, i.e. it may not be the expression of a goal-directed behavior. Contemporary analysis of instrumental behavior has shown emphatically that this is not the case under circumstances of extended training (52). Conditioned stimuli can elicit and maintain instrumental behavior directly, independent of the 
representation of the value of the goal, through the formation of stimulus-response (S-R) associations that underlie habits. The nature and importance of habits remains a matter of controversy to some authors, who confuse habits (which involve the initiation of a cognitive or behavioral sequence) with skills (which pertain to the performance of a behavioral sequence) (53). However, it has been shown in rats responding for ingestive and drug reinforcers that instrumental seeking responses persist when the reward has been devalued, providing direct evidence that the behavior is at that stage, and prior to the devaluation test, not goal-directed, but habitual (food 52, 54, drug 55, 56). As will be discussed below, a transition from goal-directed to habitual instrumental behavior is accompanied by a shift to control over that behavior by the dorsolateral striatum $(35,57)$. Moreover, using the acquisition of a new response procedure that isolates and measures conditioned reinforcement, it has been shown that responding persists after reinforcer devaluation, i.e. the conditioned reinforcing properties of the CS are resistant to devaluation of the associated primary reinforcer, whereas sign-tracking elicited by the same CS is not (58). Indeed, when rats have been responding for a cocaine-associated CS in the acquisition of new response procedure for 4-8 weeks, responding becomes sensitive to dorsolateral striatal inactivation (59), further evidencing S-R control after initial acquisition. There is considerable evidence that automatic processes underlying seeking habits emerge in humans relapsing to drug use, and that in humans, post-hoc rationalization of such behavior may underlie subjective craving $(60)$.

Having established the methodology when Markou and Arroyo worked together in Cambridge, we have gone on to use it to explore the neural basis of the impact of conditioned reinforcement on drug seeking (Figure 1G) (reviewed in detail in (61-63). We initially showed that the BLA is required for the acquisition of cocaine seeking, as we had predicted from our earlier demonstration of its key role in conditioned reinforcement (4); rats without a BLA acquired cocaine (and heroin) self-administration - hence it had no effect on primary cocaine reinforcement processes - but severely impaired cocaine seeking acquisition (64). Lesions or inactivation of the nucleus accumbens core (NAcbC) also impaired the acquisition of cocaine seeking, whereas lesions of the shell (NAcbS) did not (47), but instead abolished the potentiative effects of cocaine on conditioned reinforcement (shown in Figure 1D). The NAcb was later shown to be a critical site for mediating other amygdala-dependent Pavlovian influences on appetitive behavior $(23,65)$ and also for enabling animals to tolerate delays to reinforcement in an immediate versus delayed reward task; lesions of the NAcbC resulting in impulsive choice and intolerance of delays to reinforcement (66). We then showed that 
dopamine and glutamate-dependent functional interactions between the BLA and NAcbC are required for cocaine seeking using an asymmetric disconnection procedure (67). This has recently been confirmed by showing that the selective DREADD-mediated inhibition of this pathway prevents the seeking response-enhancing effects of contingent presentation of cocaine CSs on introduction of a second-order schedule of reinforcement (Higueras Matas, Puaud, Belin and Everitt, unpublished observations).

An important later realization was that although ventral striatal circuitry is required for the acquisition of cocaine seeking, it actually recruits and then becomes subordinate to dorsal striatal circuitry when the behavior is well established. We had initially hypothesised that while drug seeking is initiated as a goal-directed behavior, after time and multiple daily repetitions of performance of the behavior it eventually becomes controlled by S-R associative processes in the dorsal striatum, and hence our hypothesis of a transition from the ventral to the dorsal striatum of CS-controlled drug seeking over time $(68,69)$. Having initially shown that extracellular dopamine was increased in the NAcbC when cocaine CSs were presented unexpectedly and not response-contingently, but not during well established cocaine seeking under a second-order schedule, we went on to show that it was instead increased in the anterior dorsolateral striatum (aDLS) (45). This increased aDLS dopamine was shown to be causally involved, since dopamine receptor antagonism in the aDLS, but not in the NAcbC, dose-dependently reduced well-established cocaine seeking (70). In retrospect, these data were not as surprising as they seemed at the time, since the aDLS had by then been shown to be essential for S-R habit acquisition and performance of instrumental responding for ingestive rewards $(57,71)$. In addition, we demonstrated that dopamine in the dorsomedial striatum was required for the early acquisition of cocaine seeking (36), consistent with its established role in action-outcome (goal-directed) instrumental behavior (72), but that this dependence becomes subordinate to aDLS control when the behavior is well-established (36).

In investigating the mechanisms by which the transition from ventral to dorsal striatal control over behavior might occur, we tested the hypothesis that it might be mediated by the circuitry that links the nucleus accumbens with the dorsal striatum via recurrent, or spiraling, loops linking progressively more dorsal domains of the striatum through connectivity with midbrain dopamine neurons (Figure 1G) initially revealed in primates (73), but later in the rat brain (74). To demonstrate this, we employed a disconnection procedure in which a unilateral lesion of the $\mathrm{NAcbC}$ was combined with contralateral dopamine receptor 
antagonism in the aDLS. This manipulation, which disconnects the circuitry bilaterally, only impaired cocaine seeking when it was well-established; the same manipulation had no effect on instrumental reward seeking soon after acquisition, when goal-directed (35). Subsequently, using in vivo voltammetry CS-elicited cocaine seeking was shown to be associated with dopamine transients in the aDLS, but only after 3 weeks of training, whereas they are present in the NAcb from the outset. Moreover, a unilateral lesion of the NAcbC prevented the late-emerging increase in aDLS dopamine transients only on the side of the brain ipsilateral to the lesion, confirming the dependence of aDLS dopamine release on antecedent ventral striatal processing in animals responding for cocaine (75).

We have explored further the neural circuits that orchestrate these intrastriatal shifts and the associated establishment of cocaine seeking habits by using a combination of asymmetric pharmacological manipulations of the amygdala and aDLS and in vivo extracellular electrophysiological recordings (76). First, it is clear that the CS influence on drug seeking (conditioned reinforcement) initially depends on processing in the amygdala and its interactions with the NAcbC, yet ultimately depends on the aDLS to which the amygdala does not directly project. The functional recruitment of dopamine-dependent aDLS control over cocaine seeking initially depends upon the BLA, but the maintenance of the cocaine seeking habit was shown to depend on the central amygdala (CeN) and its dopamine-dependent interaction with the aDLS (76). Thus, disconnection of the BLA and aDLS impaired cocaine seeking as habitual seeking emerged, but was without effect when well established, while a CeN-aDLS disconnection had no effect early on, but resulted in disruption of cocaine seeking when well established (76). How is the underlying circuitry organized, given the absence of amygdala-aDLS connectivity? The answer is that the NAcbC is the key interface between the BLA and aDLS (Figure 1G). Thus, while stimulation of the BLA did not drive aDLS medium spiny neurons, it both up- and down-regulated the activity of these neurons driven directly by electrical stimulation of the topographically appropriate glutamatergic input from the motor cortex (M1) (76). Coincident glutamate receptor blockade in the NAcbC completely abolished the ability of the BLA to modulate aDLS neuronal activity. The latency of the gating effects of the BLA on aDLS medium spiny neuron firing (76) suggests a polysynaptic pathway involving serial connections between the ventral striatum and midbrain dopamine neurons innervating the dorsal striatum, but this circuit has yet to be mapped using pathway specific manipulations. Similarly the route via which the CeN influences aDLS function has not been demonstrated, but there is a well-established projection from the CeN to the substantia nigra that has previously been shown to have a functional role in conditioned orienting (77), while 
CeN interactions with the aDLS have been shown to play a key role in habitual responding for food (78). Thus, both CeN interactions with the aDLS and BLA interactions with the aDLS (the latter being mediated by the $\mathrm{NAcbC}$ ) likely both depend on engagement of nigral dopaminergic projections to the dorsal striatum, emphasizing again an important role for dopaminergic mechanisms in addictive behavior, but not restricted to mechanisms of reward.

The underlying neural mechanisms and circuitry that have been revealed in the experiments summarized briefly above are consistent with our underlying hypotheses that there is a transition from goal-directed to habitual drug seeking and a shift from ventral to dorsal striatal control over drug seeking during the emergence of drug addiction $(22,61,62,69)$. It has been very interesting and affirming to see the extent to which functional and structural imaging data in human and clinical studies have supported these hypotheses as we have reviewed recently $(22,79)$. In heroin, alcohol and cocaine addiction there is clear evidence of engagement of dorsal striatal mechanisms and functional coupling between ventral and dorsal striatum (80-82), as well as in a behavioral addiction, compulsive gambling (83). These data are further complemented by those demonstrating the dominant engagement of S$\mathrm{R}$ habit processes in addicted individuals (84-86). However, in no sense are rats seeking and self-administering limited numbers of cocaine infusions each day for several weeks considered to be addicted. Rats with this controlled drug intake history have developed strong, dorsal striatum, dopamine-dependent habitual behavior, but they are not compulsive. In a recent study, Leyton and colleagues (87) have explicitly tested this premise by measuring dopamine release in response to cocaine-associated CSs in recreational cocaine users who explicitly did not meet DSM criteria for severe substance use disorder (i.e. addiction). They showed significantly increased extracellular dopamine in the dorsal striatum, whereas in an early study with volunteers who had received just three doses of amphetamine, presentation of the associated CS increased dopamine in the ventral striatum. These data very closely resemble those from our earlier experiments in rats $(44,45)$. In the addicted state, cocaine cues continue to be associated with increased activation of the dorsal striatum (88), further indicating that the shift to dorsal striatal involvement in addictive behavior is associated with the emergence of S-R habits and that this precedes the development of compulsive drug use, as we have hypothesised $(22,69)$, but this has yet to be explicitly been demonstrated.

\section{Concluding remarks}

This brief review I hope reveals how a brief series of visits of Athina Markou to the Cambridge 
laboratory to immerse herself in the way we - Trevor Robbins, Tony Dickinson and I - had begun to study the neural basis of learning and memory mechanisms in addiction, and to share with us her extensive skills in drug self-administration procedures and a different theoretical approach, enabled considerable progress to be made in the more or less 25 years since. Athina was a highly enthusiastic, energetic, intelligent and committed addiction researcher who went on to make very significant contributions to the field, especially in nicotine addiction. She was also a most treasured friend who will always be missed.

\section{Acknowledgements}

This review is dedicated to the memory of Athina Markou. I express my sincere thanks to the many researchers, past and present, who have collected the data summarised briefly here in meticulously conducted experiments. I am grateful to the Medical Research Council have generously supported this research through a continuous series of programme grants. Finally, I thank David Belin for assembling Figure 1, for critical reading of the manuscript and for his major contribution to our understanding of the neural basis of drug seeking.

\section{Financial Disclosure}

I have no financial disclosures. 


\section{References}

1. Gawin FH, Kleber HD (1986): Abstinence symptomatology and psychiatric diagnosis in cocaine abusers. Clinical observations. Arch Gen Psychiatry. 43:107-113.

2. Taylor JR, Robbins T (1984): Enhanced behavioural control by conditioned reinforcers following microinjections of d-amphetamine into the nucleus accumbens. Psychopharmacology (Berl). 84:405-412.

3. Taylor JR, Robbins T (1986): 6-Hydroxydopamine lesions of the nucleus accumbens, but not of the caudate nucleus, attenuate enhanced responding with reward-related stimuli produced by intra-accumbens d-amphetamine. Psychopharmacology (Berl). 90:390-397.

4. Cador M, Robbins TW, Everitt BJ (1989): Involvement of the amygdala in stimulusreward associations: interaction with the ventral striatum. Neuroscience. 30:77-86.

5. Parkinson JA, Olmstead MC, Burns LH, Robbins TW, Everitt BJ (1999): Dissociation in effects of lesions of the nucleus accumbens core and shell on appetitive pavlovian approach behavior and the potentiation of conditioned reinforcement and locomotor activity by Damphetamine. The Journal of Neuroscience. 19:2401-2411.

6. Everitt BJ, Stacey P (1987): Studies of instrumental behavior with sexual reinforcement in male rats (Rattus norvegicus): II. Effects of preoptic area lesions, castration, and testosterone. J Comp Psychol. 101:407-419.

7. Everitt B, Fray P, Kostarczyk E, Taylor S, Stacey P (1987): Studies of instrumental behavior with sexual reinforcement in male rats (Rattus norvegicus): I. Control by brief visual stimuli paired with a receptive female. J Comp Psychol. 101:395-406.

8. Everitt BJ (1990): Sexual motivation: a neural and behavioural analysis of the mechanisms underlying appetitive and copulatory responses of male rats. Neurosci Biobehav Rev. 14:217-232.

9. Everitt BJ, Cador M, Robbins TW (1989): Interactions between the amygdala and ventral striatum in stimulus-reward associations: studies using a second-order schedule of sexual reinforcement. Neuroscience. 30:63-75.

10. Everitt BJ, Robbins TW (2000): Second-order schedules of drug reinforcement in rats and monkeys: measurement of reinforcing efficacy and drug-seeking behaviour. Psychopharmacology. 153:17-30.

11. Hogarth L, Dickinson A, Duka T (2009): Detection versus sustained attention to drug cues have dissociable roles in mediating drug seeking behavior. Exp Clin Psychopharmacol. 17:21-30. 
12. Bradley BP, Mogg K, Wright T, Field M (2003): Attentional bias in drug dependence: vigilance for cigarette-related cues in smokers. Psychol Addict Behav. 17:66-72.

13. Field M, Cox W (2008): Attentional bias in addictive behaviors: a review of its development, causes, and consequences. Drug Alcohol Depend. 97:1-20.

14. Hogarth L, Dickinson A, Janowski M, Nikitina A, Duka T (2008): The role of attentional bias in mediating human drug-seeking behaviour. Psychopharmacology. 201:29-41.

15. Tomie A, di Poce J, Derenzo C, Pohorecky L (2002): Autoshaping of ethanol drinking: an animal model of binge drinking. Alcohol Alcohol. 37:138-146.

16. Saunders B, Robinson T (2013): Individual variation in resisting temptation: implications for addiction. Neurosci Biobehav Rev. 37:1955-1975.

17. Corbit LH, Janak PH (2007): Ethanol-associated cues produce general pavlovianinstrumental transfer. Alcohol Clin Exp Res. 31:766-774.

18. Milton AL, Schramm MJW, Wawrzynski JR, Gore F, Oikonomou-Mpegeti F, Wang NQ, et al. (2012): Antagonism at NMDA receptors, but not beta-adrenergic receptors, disrupts the reconsolidation of pavlovian conditioned approach and instrumental transfer for ethanolassociated conditioned stimuli. Psychopharmacology (Berl). 219:751-761.

19. LeBlanc KH, Ostlund SB, Maidment NT (2012): Pavlovian-to-Instrumental Transfer in Cocaine Seeking Rats. Behavioral neuroscience. 126:681-689.

20. Hogarth L, Balleine B, Corbit L, Killcross S (2013): Associative learning mechanisms underpinning the transition from recreational drug use to addiction. Ann N Y Acad Sci. 1282:12-24.

21. Hogarth L, Dickinson A, Duka T (2010): The associative basis of cue-elicited drug taking in humans. Psychopharmacology (Berl). 208:337-351.

22. Everitt BJ, Robbins TW (2016): Drug Addiction: Updating Actions to Habits to Compulsions Ten Years On. Annu Rev Psychol. 67:23-50.

23. Cardinal R, Parkinson JA, Hall J, Everitt BJ (2002): Emotion and motivation: the role of the amygdala, ventral striatum, and prefrontal cortex. Neuroscience and biobehavioral reviews, 26: $321-352$.

24. Corbit L, Balleine B (2011): The general and outcome-specific forms of Pavlovianinstrumental transfer are differentially mediated by the nucleus accumbens core and shell. $J$ Neurosci. 31:11786-11794.

25. Allman MJ, DeLeon IG, Cataldo MF, Holland PC, Johnson AW (2010): Learning processes affecting human decision making: An assessment of reinforcer-selective Pavlovian- 
to-instrumental transfer following reinforcer devaluation. J Exp Psychol Anim Behav Process. 36:402-408.

26. Cardinal R, Winstanley CA, Robbins TW, Everitt BJ (2004): Limbic Corticostriatal Systems and Delayed Reinforcement. Annals of the New York Academy of Sciences. 1021:33-50. 27. Di Ciano P, Everitt BJ (2004): Conditioned reinforcing properties of stimuli paired with self-administered cocaine, heroin or sucrose: implications for the persistence of addictive behaviour. Neuropharmacology. 47 Suppl 1:202-213.

28. Mackintosh N (1974): The psychology of animal learning. Oxford: Academic Press.

29. Di Ciano P, Benham-Hermetz J, Fogg AP, Osborne GE (2007): Role of the prelimbic cortex in the acquisition, re-acquisition or persistence of responding for a drug-paired conditioned reinforcer. Neuroscience. 150:291-298.

30. Shaham Y, Shalev U, Lu L, De Wit H, Stewart J (2003): The reinstatement model of drug relapse: history, methodology and major findings. Psychopharmacology. 168:3-20.

31. Pickens C, Airavaara M, Theberge F, Fanous S, Hope B, Shaham Y (2011): Neurobiology of the incubation of drug craving. Trends Neurosci. 34:411-420.

32. Arroyo M, Markou A, Robbins TW, Everitt BJ (1998): Acquisition, maintenance and reinstatement of intravenous cocaine self-administration under a second-order schedule of reinforcement in rats: effects of conditioned cues and continuous access to cocaine. Psychopharmacology (Berl). 140:331-344.

33. Markou A, Arroyo M, Everitt B (1999): Effect of contingent and non-contingent cocaine on drug-seeking behavior measured using a second-order schedule of cocaine reinforcement in rats. Neuropsychopharmacology. 20:542-555.

34. Alderson H, Robbins TW, Everitt BJ (2000): Heroin self-administration under a secondorder schedule of reinforcement: acquisition and maintenance of heroin-seeking behaviour in rats. Psychopharmacology. 153:120-133.

35. Belin D, Everitt BJ (2008): Cocaine seeking habits depend upon dopamine-dependent serial connectivity linking the ventral with the dorsal striatum. Neuron. 57:432-441.

36. Murray JE, Belin D, Everitt BJ (2012): Double dissociation of the dorsomedial and dorsolateral striatal control over the acquisition and performance of cocaine seeking. Neuropsychopharmacology. 37:2456-2466.

37. Giuliano C, Robbins TW, Wille DR, Bullmore ET, Everitt BJ (2013): Attenuation of cocaine and heroin seeking by mu-opioid receptor antagonism. Psychopharmacology (Berl). 227:137-147. 
38. Giuliano C, Goodlett CR, Economidou D, Garcia-Pardo MP, Belin D, Robbins TW, et al. (2015): The Novel mu-Opioid Receptor Antagonist GSK1521498 Decreases Both Alcohol Seeking and Drinking: Evidence from a New Preclinical Model of Alcohol Seeking. Neuropsychopharmacology. 40:2981-2992.

39. Goldberg SR, Kelleher RT, Morse WH (1975): Second-order schedules of drug injection. Fed Proc. 34:1771-1776.

40. Goldberg SR (1973): Comparable behavior maintained under fixed-ratio and secondorder schedules of food presentation, cocaine injection or d-amphetamine injection in the squirrel monkey. J Pharmacol Exp Ther. 186:18-30.

41. Goldberg SR, Spealman RD, Kelleher RT (1979): Enhancement of drug-seeking behavior by environmental stimuli associated with cocaine or morphine injections. Neuropharmacology. 18:1015-1017.

42. Panlilio L, Yasar S, Nemeth-Coslett R, Katz J, Henningfield J, Solinas M, et al. (2005): Human cocaine-seeking behavior and its control by drug-associated stimuli in the laboratory. Neuropsychopharmacology. 30:433-443.

43. Goldberg SR, Morse WH, Goldberg DM (1976): Behavior maintained under a secondorder schedule by intramuscular injection of morphine or cocaine in rhesus monkeys. $J$ Pharmacol Exp Ther. 199:278-286.

44. Ito R, Dalley J, Howes SR, Robbins TW, Everitt BJ (2000): Dissociation in Conditioned Dopamine Release in the Nucleus Accumbens Core and Shell in Response to Cocaine cues and during Cocaine-Seeking Behavior in rats. Journal of Neuroscience. 19:7489-7495.

45. Ito R, Dalley J, Robbins T, Everitt B (2002): Dopamine release in the dorsal striatum during cocaine-seeking behavior under the control of a drug-associated cue. J Neurosci. 22:6247-6253.

46. Di Ciano P, Everitt B (2002): Reinstatement and spontaneous recovery of cocaineseeking following extinction and different durations of withdrawal. Behavioural Pharmacology. 13:397-405.

47. Ito R, Robbins T, Everitt B (2004): Differential control over cocaine-seeking behavior by nucleus accumbens core and shell. Nat Neurosci. 7:389-397.

48. Markou A, Weiss F, Gold LH, Caine SB, Schulteis G, Koob G (1993): Animal models of drug craving. Psychopharmacology (Berl). 112:163-182.

49. Robinson TE, Berridge KC (1993): The neural basis of drug craving: an incentivesensitization theory of addiction. Brain Res Brain Res Rev. 18:247-291. 
50. Grimm JW, Hope BT, Wise RA, Shaham Y (2001): Incubation of cocaine craving after withdrawal. Nature. 412:141-142.

51. Wolf ME (2016): Synaptic mechanisms underlying persistent cocaine craving. Nat Rev Neurosci. 17:351-365.

52. Adams C, Dickinson A (1981): Instrumental responding following reinforcer devaluation. Q J Exp Psychol Comp Physiol Psychol. 33:109-121.

53. Piazza P, Deroche-Gamonet V (2013): A multistep general theory of transition to addiction. Psychopharmacology (Berl). 229:387-413.

54. Balleine B, Paredes-Olay C, Dickinson A (2005): Effects of outcome devaluation on the performance of a heterogeneous instrumental chain. International journal of comparative psychology. 18:257-272.

55. Zapata A, Minney V, Shippenberg T (2010): Shift from goal-directed to habitual cocaine seeking after prolonged experience in rats. J Neurosci. 30:15457-15463.

56. Corbit LH, Chieng BC, Balleine BW (2014): Effects of repeated cocaine exposure on habit learning and reversal by N-acetylcysteine. Neuropsychopharmacology. 39:1893-1901.

57. Yin HH, Knowlton BJ, Balleine BW (2004): Lesions of dorsolateral striatum preserve outcome expectancy but disrupt habit formation in instrumental learning. European Journal of Neuroscience. 19:181-189.

58. Parkinson JA, Roberts AC, Everitt B, Di Ciano P (2005): Acquisition of instrumental conditioned reinforcement is resistant to the devaluation of the unconditioned stimulus. QJExpPsycholB. 58:19-30.

59. Di Ciano P, Robbins TW, Everitt BJ (2008): Differential Effects of Nucleus Accumbens Core, Shell, or Dorsal Striatal Inactivations on the Persistence, Reacquisition, or Reinstatement of Responding for a Drug-Paired Conditioned Reinforcer. Neuropsychopharmacology. 33:1413-1425.

60. Tiffany ST (1990): A cognitive model of drug urges and drug-use behavior: role of automatic and nonautomatic processes. Psychol Rev. 97:147-168.

61. Belin D, Jonkman S, Dickinson A, Robbins TW, Everitt BJ (2009): Parallel and interactive learning processes within the basal ganglia: relevance for the understanding of addiction. Behav Brain Res. 199:89-102.

62. Everitt BJ, Robbins TW (2013): From the ventral to the dorsal striatum: devolving views of their roles in drug addiction. Neurosci Biobehav Rev. 37: 1946-1954 
63. Everitt BJ (2014): Neural and psychological mechanisms underlying compulsive drug seeking habits and drug memories--indications for novel treatments of addiction. Eur $J$ Neurosci. 40:2163-2182.

64. Whitelaw RB, Markou A, Robbins TW, Everitt BJ (1996): Excitotoxic lesions of the basolateral amygdala impair the acquisition of cocaine-seeking behaviour under a secondorder schedule of reinforcement. Psychopharmacology (Berl). 127:213-224.

65. Everitt BJ, Cardinal RN, Parkinson JA, Robbins TW (2003): Appetitive Behavior Impact of Amygdala-Dependent Mechanisms of Emotional Learning. Annals of the New York Academy of Sciences. 985:233-250.

66. Cardinal RN, Pennicott DR, Sugathapala CL, Robbins TW, Everitt BJ (2001): Impulsive choice induced in rats by lesions of the nucleus accumbens core. Science. 292:2499-2501.

67. Di Ciano P, Everitt BJ (2004): Direct Interactions between the Basolateral Amygdala and Nucleus Accumbens Core Underlie Cocaine-Seeking Behavior by Rats. Journal of Neuroscience. 24:7167-7173.

68. Robbins TW, Everitt BJ (1999): Drug addiction: bad habits add up. Nature. 398:567570.

69. Everitt BJ, Robbins TW (2005): Neural systems of reinforcement for drug addiction: from actions to habits to compulsion. Nat Neurosci. 8:1481-1489.

70. Vanderschuren L, Di Ciano P, Everitt B (2005): Involvement of the dorsal striatum in cue-controlled cocaine seeking. J Neurosci. 25:8665-8670.

71. Yin H, Knowlton B, Balleine B (2006): Inactivation of dorsolateral striatum enhances sensitivity to changes in the action-outcome contingency in instrumental conditioning. Behavioural Brain Research. 166:189-196.

72. Yin HH, Ostlund SB, Knowlton BJ, Balleine BW (2005): The role of the dorsomedial striatum in instrumental conditioning. Eur J Neurosci. 22:513-523.

73. Haber S, Fudge J, McFarland N (2000): Striatonigrostriatal pathways in primates form an ascending spiral from the shell to the dorsolateral striatum. J Neurosci. 20:2369-2382.

74. Ikemoto S (2007): Dopamine reward circuitry: Two projection systems from the ventral midbrain to the nucleus accumbens-olfactory tubercle complex. Brain Research Reviews. 56:27-78.

75. Willuhn I, Burgeno LM, Everitt BJ, Phillips PE (2012): Hierarchical recruitment of phasic dopamine signaling in the striatum during the progression of cocaine use. Proc Natl Acad Sci U S A. 109:20703-20708. 
76. Murray JE, Belin-Rauscent A, Simon M, Giuliano C, Benoit-Marand M, Everitt BJ, et al. (2015): Basolateral and central amygdala differentially recruit and maintain dorsolateral striatum-dependent cocaine-seeking habits. Nat Commun. 6:10088.

77. El-Amamy H, Holland P (2007): Dissociable effects of disconnecting amygdala central nucleus from the ventral tegmental area or substantia nigra on learned orienting and incentive motivation. Eur J Neurosci. 25:1557-1567.

78. Lingawi NW, Balleine BW (2012): Amygdala central nucleus interacts with dorsolateral striatum to regulate the acquisition of habits. J Neurosci. 32:1073-1081.

79. Everitt BJ, Giuliano C, Belin D (2017): Addictive behaviour in experimental animals: prospects for translation. Philisophical Transactions of the Royal Society, B. DOI: 10.1098/rstb. 2017.0027

80. Xie C, Shao Y, Ma L, Zhai T, Ye E, Fu L, et al. (2014): Imbalanced functional link between valuation networks in abstinent heroin-dependent subjects. Mol Psychiatry. 19:10-12.

81. Vollstadt-Klein S, Wichert S, Rabinstein J, Buhler M, Klein O, Ende G, et al. (2010): Initial, habitual and compulsive alcohol use is characterized by a shift of cue processing from ventral to dorsal striatum. Addiction. 105:1741-1749.

82. Sjoerds Z, de Wit S, van den Brink W, Robbins TW, Beekman ATF, Penninx BWJH, et al. (2013): Behavioral and neuroimaging evidence for overreliance on habit learning in alcoholdependent patients. Translational Psychiatry. DOI: 10.1038/tp.2013.107

83. Liu L, Yip SW, Zhang JT, Wang LJ, Shen ZJ, Liu B, et al. (2017): Activation of the ventral and dorsal striatum during cue reactivity in Internet gaming disorder. Addict Biol. 22:791-801. 84. Bohbot V, Del Balso D, Conrad K, Konishi K, Leyton M (2013): Caudate nucleusdependent navigational strategies are associated with increased use of addictive drugs. Hippocampus. 23:973-984.

85. Ersche KD, Gillan CM, Jones PS, Williams GB, Ward LH, Luijten M, et al. (2016): Carrots and sticks fail to change behavior in cocaine addiction. Science. 352:1468-1471.

86. Donamayor N, Strelchuk D, Baek K, Banca P, Voon V (2017): The involuntary nature of binge drinking: goal directedness and awareness of intention. Addict Biol.

87. Cox SML, Yau Y, Larcher K, Durand F, Kolivakis T, Delaney JS, et al. (2017): Cocaine Cue-Induced Dopamine Release in Recreational Cocaine Users. Sci Rep. 7:46665.

88. Volkow N, Wang GJ, Telang F, Fowler JS, Logan J, Childress AR, et al. (2006): Cocaine Cues and Dopamine in Dorsal Striatum: Mechanism of Craving in Cocaine Addiction. Journal of Neuroscience. 26:6583-6588. 
BJ Everitt. Biological Psychiatry special issue to commemorate Athina Markou, 2017 
Figure 1. Behavioral characteristics of cocaine seeking under a second-order schedule of reinforcement and the underlying limbic corticostriatal circuitry

1A. Schematic illustration of rats responding for a cocaine-associated light conditioned reinforcer (under a FR10 schedule; i.e.10 active lever presses, ALP) prior to receiving an i.v. infusion of cocaine after a 15 minute fixed interval. 1B The effects of introducing a cocaine CS contingent on every 10 lever presses. In the initial 3 sessions, rats are responding under a Fixed Interval 15 minutes schedule (FI15). On introduction of the CS (sessions 5-10) under FR 10 there is a near quadrupling of seeking responses per 15 minutes (FI15:FR10S secondorder schedule). Omitting the CS (CSO) results in a marked decrease in seeking responses (session 11). 1C. The decrease in seeking responses over 3 days of CS omission from a Pre-CS omission baseline. Seeking responses increase promptly on reintroduction of the cocaine CS. 1D In the first (pre-cocaine infusion) interval of a FI15:FR10S second order schedule is linearly related to drug dose. $1 \mathrm{E} \& \mathrm{~F}$. An individual cumulative response record in a rat responding under FI15:FR10S. Each Fixed Ratio 10 responses results in illumination of the light CS, which early in the 15 minute interval is followed by a post-stimulus pause in responding (i.e. a post conditioned reinforcement pause). As the interval progresses, responding becomes more or less continuous until cocaine is infused on completion of a FR10 of responses after the Fixed Interval has timed out. After the cocaine infusion, in the $2^{\text {nd }} 15$ minute interval, seeking responses are greatly increased, reflecting the effect of cocaine to enhance conditioned reinforcement, an effect that depends on the integrity of the nucleus accumbens shell. 1G. Summary of the circuitry underlying cocaine seeking. Illustrated are basolateral amygdala (BLA) projections to the nucleus accumbens core (AcbC), required for acquisition of cocaine seeking through the mediation of conditioned reinforcement and tolerance of delays to reinforcement. The spiraling circuitry linking nucleus accumbens with more dorsal striatal zones - dorsomedial striatum (DMS) with its afferents from the orbitofrontal cortex (OFc) and the dorsolateral striatum (DLS) is shown as alternating arrows. The DMS is required for the early acquisition of cocaine seeking when goal-directed; the DLS is required for well-established cocaine seeking when under stimulus-response (habitual) control. 


\section{In this issue statement.}

This review pays tribute to a collaboration with Athina Markou 25 years ago and the fruits of that collaboration in research carried out subsequently and up to the present day. This research established a method of measuring drug seeking and the impact of drug-associated stimuli acting as conditioned reinforcers. This methodology has enabled the elucidation of the neural mechanisms underlying drug seeking and the transitions from goal-directed to habitual behavior. 